\title{
SOBRE REQUISITOS DE FORMAÇÃO SUPERIOR EM ARTES CÊNICAS: O ARTISTA COMO EMPREENDEDOR
}

\author{
Prof. Dr. Gláucio Machado Santos ${ }^{1}$ \\ Doutor em Artes Cênicas \\ PPGAC-UFBA \\ glaucio@mail.com
}

Neste trabalho, congrego e consolido observações já esboçadas nas comunicações $U m$ certo olhar sobre a pré-encenação e $O$ diretor teatral como empreendedor: perspectiva histórica e sugestões de formação apresentadas respectivamente no VI Congresso da Associação Brasileira de Pesquisa e Pós-Graduação em Artes Cênicas (ABRACE) e na VI Reunião Científica da mesma entidade. Desta forma, o presente artigo apresenta-se como resultado final das atividades do projeto de pesquisa intitulado Encenação: práticas de ensino e caminhos para a sustentabilidade ligado ao Grupo de Pesquisa em Encenação Contemporânea (G-PEC) registrado no CNPq.

Pretendo contribuir para um início de reflexão acerca de novos conteúdos transdisciplinares na formação dos artistas cênicos no Brasil. A necessidade de tal incremento nasce de minha experiência como docente em nível superior na área e tem como inspiração as considerações das professoras Edinice Mei Silva e Lessandra Scherer Severo, constantes no resumo do artigo Sistema Stanislavski: o processo criativo nas organizações, da área de Ciências da Administração:

Grande parte dos problemas enfrentados pelas organizações, no atual quadro econômico e comercial, já não aceita soluções anteriormente utilizadas. Isso impõe à sociedade a necessidade de desenvolver a criatividade na busca de diferenciação profissional e organizacional. Dito isto, o presente artigo busca, através de pesquisa teórica, explorar de forma interdisciplinar a interação de duas áreas: Artes Cênicas e Ciências da Administração. (SEVERO e SILVA, 2006:s/p) 
A constatação das professoras indica uma possibilidade de interação que, em minha pesquisa, serve de base para um raciocínio em outro sentido. Se, por um lado, há um esgotamento de soluções detectado dentro das organizações, por outro, há uma séria carência de recursos de gestão no âmbito da criação e manutenção de espetáculos teatrais no Brasil por parte dos iniciantes na área. Tal insuficiência é fruto de uma formação que afasta o artista da intimidade com trâmites administrativos.

Da mesma forma que as docentes percebem a interação dessas duas áreas como fonte criativa para questões em Ciências da Administração, acredito que essa mesma interação oferece preciosos conteúdos para a construção da noção de empreendedorismo nas Artes Cênicas, encaminhando assim reais oportunidades de sustentabilidade para as realizações de artistas recém formados. Enfatizo que a intimidade com a gestão não é estranha à tradição de criação nessa área. Para demonstrar esses laços, inicio uma revisão sobre o passado do Teatro.

Começo minhas considerações históricas a partir da sugestão de Ênio Carvalho, ao acenar para uma proto-história de nossa arte cênica, por volta de 3.000 a.C., segundo a qual:

\begin{abstract}
As manifestações religiosas do antigo Egito já conotavam a possibilidade de uma continuidade cênica, em que um ser desencarnado poderia readquirir vida através de um ser vivo. Assim, as representações dos mistérios, como dramas litúrgicos, nas cerimônias funerárias do culto do deus Osíris prenunciavam os rituais dionisíacos, que seriam os precursores do teatro grego [...] Tanto a anunciação das personagens quanto suas evoluções cênicas estariam previamente escritas para que os espectadores pudessem distinguir os locais designados na sucessão das cenas. (CARVALHO, 1989, p.14)
\end{abstract}

Sobre tais manifestações, Nelson de Araújo salientava igualmente as descobertas com relação à organização de representações litúrgicas no Egito Antigo:

Descobertas relativamente recentes, a que se associaram os nomes dos pesquisadores Etienne Drioton, Kurt Sethe e outros mais próximos, deram conta da existência de representações litúrgicas no Egito antigo, confirmando assim indicações do historiador grego Heródoto. (ARAÚJO, 1991,p.69)

Quanto a isso, Margot Berthold destaca que "os estágios do destino de Osíris constituem as estações do grande mistério de Abidos. Os sacerdotes organizavam a peça e 
atuavam nela. O clero percebia quão vastas possibilidades de sugestão das massas o mistério oferecia" (BERTHOLD, 2001, p.11). Já no Egito Antigo, constata-se uma inquietação quanto ao comportamento do público em face da cena religiosa. A atenção do sacerdote egípcio objetivava levantar elementos para aperfeiçoar o desempenho do conjunto e com isso criar um espetáculo cuja recepção disseminasse no povo a vontade e a verdade do faraó. Conforme indica Léon Moussinac, tais encenações tinham um cunho assumidamente político: "Podemos mesmo pensar, segundo as indicações que possuímos, que ele [o teatro egípcio antigo] teria, por vezes, um sentido político, que se afirmava, sobretudo fora do templo" (MOUSSINAC, 1957, p.35).

Ainda com atenção sobre esse momento, a professora Robyn Gillam (2006) organiza uma pesquisa visando discutir a performance realizada à época. Por intermédio de seu trabalho, pude perceber também que a elaboração de cortejos públicos em Abidos tem íntima ligação com a necessidade de disseminação da ideologia que sustenta a credibilidade do faraó perante o povo. A partir daí, cria-se uma rede de interesses para que essa representação aconteça. Assim sendo, já nos primórdios da elaboração de cenas teatrais, consolida-se a necessidade de negociar e arregimentar recursos físicos para a efetivação da obra.

Richard Schechner indica que "Via Creta e outras rotas mediterrâneas os gregos tiraram muito dos egípcios incluindo-se a ideia de que o teatro é um festival: algo que acontece num momento especial e em um lugar especial"”2 (SCHECHNER, 1973, p.21). Não se pode ignorar o fato de o Egito ter sido colônia da Grécia. Haja vista a proximidade geográfica veicularam-se inúmeros intercâmbios por pelo menos mil anos desde as manifestações religiosas de Abidos até as Grandes Dionisíacas.

Considero como um aprimoramento da atenção do sacerdote-diretor egípcio a consciente perspicácia do tragediógrafo e do corus didascalus grego ao encarar o espetáculo teatral per si como um meio especial de comunicação com o povo, como ressalta Moussinac: "A epopéia e a religião nunca deixaram de secundar esse teatro, de tal forma que Plutarco se permitirá qualificar a tragédia pré-esquiliana « de instrumento de educação dos Gregos »" (MOUSSINAC, 1957, p.38). 
Com isso, a relação do dramaturgo grego com o corega, seu financiador, está imersa numa rede de interesses que opera no nível político-social e cujos princípios podem ser identificados já no Antigo Egito. Dessa forma, aquele que organiza a cena, ou que constrói o espetáculo, tem a responsabilidade de estar à frente de um empreendimento com sérios impactos. Essa consciência se estabelece da mesma maneira e ao mesmo tempo em que a primeiras convenções da cena são construídas. Aliás, tal capacidade de gestão e negociação pode ser vista como uma "convenção" extra palco.

Michel Pruner (2005) salienta igualmente a complexidade da "fábrica" teatral e todos os elementos que interferem na sua realização desde os primórdios dessa atividade. Propositadamente, esse autor utiliza o termo "fábrica" para qualificar o seu objeto de estudo devido aos intricados desdobramentos ligados ao ato de elaborar um espetáculo. A produção de peças, ou a organização da cena mais especificamente, aprimorou-se em função de sua relação direta com as variadas realidades sociais onde o teatro se desenvolvia. As nítidas diferenças de temperamento das sociedades na Grécia e em Roma determinaram mudanças profundas na estrutura das apresentações. Ainda segundo o autor constata-se a relação direta da transformação do espaço teatral com essas condições. As modificações observadas pelo autor refletem as palavras de Jean Duvignaud quando observa que as artes cênicas "se constituem como uma arte 'enraizada', a mais engajada de todas as artes na trama viva da experiência coletiva, a mais sensível às convulsões que abalam uma vida social em estado permanente de revolução" (DUVIGNAUD apud SOARES DOS SANTOS, 1994, p.71).

Os caracteres da sociedade romana vão ditar um novo ambiente dentro do qual os artistas cênicos terão que desenvolver as suas habilidades como empreendedores. O termo dominus gregis aplicava-se para designar o diretor teatral, enquanto que o curule aediles era o responsável pela fiscalização e realização das mais variadas obras públicas, incluindo-se o pagamento de subsídios aos grupos teatrais. Lúcio Ambivius Túrpio dirigiu peças de Terêncio em sua companhia. Segundo Margot Berthold: “A troupe de Túrpio tinha boa reputação junto ao curule aediles e como dominus gregis sabia de que maneira conduzir ao sucesso as comédias por ele recomendadas" (BERTHOLD, 2001, p.48). Nota-se, dessa forma, uma contribuição dos conhecimentos de organização cênica para a boa recepção de um evento teatral. Uma vez que os textos eram compartilhados, essa condução e a capacidade de 
negociação dos diretores distinguiam as trupes. Cabia ao dominus gregis dominar a estrutura de construção do espetáculo, inclusive no âmbito dos recursos financeiros e materiais, com o intuito de levar a sua encenação ao sucesso de público. Esse domínio incluía a capacidade de negociação com o curule aediles de modo a obter o financiamento e as autorizações necessárias para suas as apresentações.

$\mathrm{O}$ apelo do sucesso levou o teatro romano a condições extremas de práticas teatrais. $\mathrm{O}$ deboche, a crueldade, a ousadia, as obscenidades, os excessos tomaram conta das apresentações e, ao serem enaltecidos pelo gosto dos romanos, acabaram por determinar uma modificação total da cena:

\begin{abstract}
Faziam-se apostas nas corridas de cavalos; e os pugilatos, os combates de gladiadores, as batalhas navais em miniatura, realizadas dentro dos anfiteatros, e todos os festejos, onde, quase sempre se derramava sangue humano, eram tomados como uma espécie de droga, cuja dose se tornava indispensável aumentar em virtude do hábito. Tais espectáculos haviam começado, em fins da República, com verdadeiros deboches de mise-en-scène: depressa, porém, o povo exigiu que sangue verdadeiro corresse e mortes autênticas se dessem. E tão bestial realismo destruiu por completo a virtuosa purificação que é a ficção, humilhando assim a Arte. (PIGNARRE, 1979, p.44)
\end{abstract}

Um dos alvos prediletos desse "bestial realismo", os cristãos sofreram inúmeros insultos. Com a ascensão da Igreja na Europa, o teatro fica banido dos palcos construídos e das apresentações oficiais em retaliação a todo o escárnio e toda a falta de respeito típicos dos espetáculos latinos. Chega-se a supor que a atividade tenha sido totalmente esquecida. John Gassner delimita o teatro como "trancado a sete chaves" do séc. V ao séc. X e indica que a "Igreja conseguira suplantar por completo o templo de Dionisos" (GASSNER, 1974, p.157). No entanto, é preciso notar a permanência da atividade teatral durante toda a Idade Média. Trabalhos como o de Mikhail Bakhtin permitem o reconhecimento de intensa produção artística popular no período (BAKHTIN, 1987). Carlo Ginzburg, ao comentar os estudos de Bakhtin, sustenta que:

[...] os protagonistas da cultura popular que ele tentou descrever - camponeses, artesãos - nos falam quase só através das palavras de Rabelais. É justamente a riqueza das perspectivas de pesquisa indicadas por Bakthin que nos faz desejar, ao contrário, uma sondagem direta, sem intermediários, do mundo popular. Porém, pelos motivos já levantados, substituir uma estratégia de pesquisa indireta por outra direta, neste tipo de trabalho, é por demais difícil. (GINZBURG, 1987, p.21) 
O próprio Gassner (1974) termina por reconhecer a permanência da arte cênica da rua, a arte do "vagamundo"; porém, a falta de documentação direta, conforme indicada por Ginzburg, incentivou a percepção de um hiato na produção teatral.

Já pelos fins da Idade Média, nas regiões onde se encontram hoje países como Alemanha, Itália, França, Rússia, Hungria e Polônia, mecenas aristocráticos abrigaram em seus palácios não somente os eventos artísticos como também os seus processos de criação. A arte teatral que sobreviveu na rua foi paulatinamente sendo abrigada no interior dos palácios e fortificações.

Catarina de Médicis tornou-se figura com destaque dentre esses incentivadores devido ao seu grande apreço pelas apresentações na corte e à sua preocupação em fornecer uma estrutura que permitisse o melhor desenvolvimento desses espetáculos. Ela é, inclusive, apontada como a grande responsável pela consolidação do balé clássico, principalmente em função de suas determinações quando se tornou monarca na França:

O germe daquilo que se converteria no balé foi levado à França por Catarina de Médicis [...] a rainha então importou da Itália artistas e cortesãos especializados na preparação de luxuosos espetáculos, e lhes encomendou um sem-número de diversões [...] O espetáculo era uma combinação de dança, canto e textos falados, e seu objetivo era claramente social e político: um passatempo elegante para o monarca e sua corte. (FARO, 1986, p. 32)

Em determinados casos, grupos de teatro já formados eram convidados a instalar as suas atividades e as suas sedes dentro dos castelos. Em outras circunstâncias, o próprio nobre selecionava artista por artista, formando elencos, orquestras e ensembles de balé. Também como exemplo, registro a iniciativa do príncipe Joseph Esterházy, membro da família mais rica do Império Austro-Húngaro. No Castelo de Joseph Esterhaz, havia um teatro com aproximadamente 180 lugares onde trabalhavam inúmeros artistas de diversas áreas, dentre eles Joseph Haydn. No livro sobre a vida do compositor, Pierre Barbaud (1960), menciona o contrato de trabalho, com catorze parágrafos, dos quais doze eram sobre as obrigações de Haydn e apenas dois indicavam a sua remuneração.

Os contratados serviam exclusivamente ao seu patrão, sobrevivendo apenas às custas desse. Como consequência, as edificações da realeza abrigaram salas de espetáculos, muitas 
vezes extremamente bem equipadas, construídas segundo as necessidades profissionais dos artistas residentes, mas também limitadas pelos recursos financeiros e pelos interesses de seus mantenedores.

Já na Grã-Bretanha, à época elisabetana, as trupes teatrais eram convidadas apenas para realizar representações dentro dos castelos durante as festas da nobreza. Conforme Paterson (1961) tais apresentações ocorriam em salões adaptados, havendo, no máximo, um depósito de materiais cenográficos nos palácios sob a responsabilidade do Master of Revels Office; uma espécie de chefe, produtor, organizador e censor das peças montadas nessas ocasiões. Portanto, todas as construções destinadas aos espetáculos de teatro, como The Globe Theatre, The Swan Theatre ou The Rose Theatre, constituíam iniciativas individuais, cujos elencos e técnicos eram mantidos graças à remuneração obtida pela receita de bilheteria e pelos cachês recebidos por suas apresentações encomendadas.

A gerência do edifício teatral como negócio obrigatoriamente lucrativo e sustentável nasce na Inglaterra já no período elisabetano. Ela foi estimulada pela falta de abrigo sob os auspícios da realeza para as companhias conceberem realizações teatrais mais permanentes. Essa conjuntura acabou por incentivar um regime de produção orientado para cada espetáculo como aglutinador momentâneo de artistas e técnicos. Dependendo do sucesso de público de cada peça, a próxima poderia contar com a mesma equipe ou não.

Acredito evidenciar com os recortes e a leitura encaminhada até o momento a íntima ligação da atividade teatral com habilidades de gestão dentro de ambientes sociais os mais diversos. Tais habilidades indicam aspectos que podem ser reconhecidos, hoje, na realidade do mercado teatral brasileiro. A articulação de projetos para editais com diretrizes políticas como contrapartidas sociais, a capacidade de busca de financiamento, o discurso junto à iniciativa privada, a utilização de leis de incentivo são exigências para a inserção do artista de teatro no mercado. Sublinho que a figura do produtor isolado ainda existe, mas é cada vez maior a necessidade de o ator ou o diretor estar à frente de seus empreendimentos, num exercício próximo ao do teatro elisabetano ou romano. 
Em paralelo a tal constatação, lembro do fato de termos cursos superiores para interpretação e direção teatral inseridos no âmbito universitário. Essa característica deveria ser melhor aproveitada na medida em que os alunos têm a oportunidade de aprender também no ambiente das Escolas de Administração. O trânsito de docentes e discentes poderia suprir demandas na interseção das áreas, enriquecendo os currículos de ambas as partes e preparando o jovem artista para melhor dialogar com a realidade brasileira de produção teatral.

Enfatizo que não se trata apenas de treinar o aluno para a gestão ou de obrigá-lo a aceitar a realidade de mercado como uma regra a ser seguida. Trata-se, pois, de prepará-lo para o diálogo, fazê-lo conhecer também as necessidades e as soluções inerentes ao processo de criação teatral como empreendimento. Dentro desse aprendizado, o artista desenvolve argumentos e práticas para interferir na dita realidade, transformando-a como agente produtivo. Assim sendo, a ideia da arte como ofício, cujos meios de viabilização físicofinanceira são conhecidos pelo artista, é inseparável da tradição do próprio teatro.

De fato, a consolidação das casas de espetáculos como espaços de contratação de artistas e a emergência dos produtores independentes tanto na Europa quanto nos EUA sugeriram uma estrutura curricular para o ensino de Artes Cênicas onde o aprendiz é preparado para ser um empregado. No entanto, estabelecer-se como "um empregado" não é a colocação oferecida pelas oportunidades de trabalho em teatro encontradas na maioria das cidades brasileiras.

Por outro lado, os egressos dos cursos Licenciatura em Teatro encontram, sim, uma rede de escolas, sejam públicas ou privadas, que proporcionam a sua inserção como empregado. O emprego, no sentido profissional da palavra, existe para o licenciado de modo totalmente diferente em relação ao bacharel.

Faz-se necessário mudar o paradigma do ensino de Artes Cênicas nos bacharelados para uma formação que também ressalte a capacidade de obter e lidar com os mais diversos recursos. Um sintoma nítido de tal carência é o crescente número de montagens com poucos atores e quase ausência de cenários. Na maioria dos casos, a opção pela simplicidade e pela 
diminuição dos componentes do elenco não tem sido fruto de uma autenticidade artística, ou de uma poética própria. Ela é o resultado da falta de capacidade de obter materiais e lidar com diferentes agendas de atores, o que leva o aluno a escolher trabalhar com menos pessoas e dispensar qualquer ambientação cenográfica mais complexa.

A dificuldade de conciliar horários e o desafio de levantar subsídios físico-financeiros são parte integrante do labor do artista cênico desde os primórdios do seu ofício. A sua atividade é coletiva e, assim sendo, os problemas advindos dessa qualidade devem ser trazidos como foco num processo de aprendizado.

À medida que melhor soubermos aproveitar a oportunidade de estar dentro de uma instituição como a universidade, o pensamento sobre a formação do ator e do diretor poderá incorporar o paradigma do empreendedorismo na concepção da grade curricular. O diálogo com os meios de gestão e financiamento atuais determina conteúdos basilares na preparação do jovem artista. Tal inclusão seria veiculada ao oferecermos uma leitura do passado da atividade teatral sob a sua ótica produtiva, como uma fábrica, a exemplo do título da obra de Michel Pruner: La fabrique du théâtre.

Um outro sintoma dessa carência de instrumentos para o artista iniciante se sustentar com a atividade teatral é a crescente migração de atores e diretores para o eixo Rio-São Paulo. Se analisarmos os valores para manter-se nas cidades de origem, veremos que seria muito mais viável para o artista permanecer; no entanto, ele migra. A razão dessa escolha é a falta de mercado local. Porém, quem constrói esse mercado é o próprio artista. A gestão dos grupos de teatro, a capacidade que o grupo tem de manter seus componentes, o circuito de festivais, as turnês, todos esses são conteúdos que auxiliariam a manutenção de artistas em seus locais de origem como agentes fomentadores de cultura.

O teatro de grupo não é o mote central do presente artigo, mas é assunto crucial para a efetivação da mudança aqui proposta. Como suporte para tal movimento, menciono a tese de Edinice Mei Silva: A organização excelente: diretrizes para o grupo teatral, a dissertação de Flávia Janiaski Vale: Produção e gestão no teatro de grupo como forma de construção de autonomia, e a atual pesquisa de Doutorado de Karina de Faria, em curso no PPGAC-UFBA, 
a qual pretende descrever estratégias de sustentabilidade de um grupo de circo-teatro nordestino desde o início do século XX até a década de 30. Todas essas investigações e seus resultados apontam para soluções que visam a autonomia do artista como profissional produtivo na sociedade.

Por fim, menciono o livro da professora Moema Renart de Brito, Manual de administração teatral, que inaugura nossa bibliografia sobre as questões da produção teatral no Brasil. De modo direto, a professora avisa que talvez pareça dissonante ou fora de lugar recorrer a conceitos de administração para tentar refletir sobre a produção teatral naquela época. Porém, ela avisa o quanto essas noções podem auxiliar o artista na sua labuta. Com a mesma perspectiva, encerro estas linhas reconhecendo que pode parecer estranho enfatizar conceitos de gestão como foco de aprendizado em Artes Cênicas.

Faço isso porque, se podemos perceber o teatro por sua qualidade sagrada, sinto-me estimulado a percebê-lo pelo seu lado mundano, aquele que viabiliza de fato a realização da obra.

\footnotetext{
${ }^{1}$ Ator, produtor e encenador. Professor do quadro permanente do PPGAC-UFBA, lotado no Departamento de Técnicas do Espetáculo da Escola de Teatro da UFBA. Atua nas áreas de produção cultural, direção teatral e processos de ensino em Artes Cênicas.

${ }^{2}$ Tradução minha. No original: "Via Crete and other Mediterranean stepping-stones the Greeks took much from the Egyptians including the idea that the theater is a festival: something that exists at a special time in a special place".
}

\section{REFERÊNCIAS}

ARAÚJO, Nelson de. História do teatro. Salvador: Empresa Gráfica da Bahia, 1991.

BARBAUD, Pierre. Joseph Haydn: in selbstzeugnissen und bilddokumenten. Reinbek (Alemanha): Rowohlt, 1960. 
BAKHTIN, Mikhail. Cultura popular na Idade Média: o contexto de François Rabelais. São Paulo: Hucitec, 1987.

BERTHOLD, Margot. História mundial do teatro. trad. de Maria Paula Zurawsdi, J. Guinsburg, Sergio Coelho e Clóvis Garcia. São Paulo: Perspectiva, 2001.

BRITO, Moema Renart de. Manual de administração teatral. Rio de Janeiro: Serviço Nacional de Teatro, 1972.

CARVALHO, Enio. História e Formação do Ator. São Paulo: Ática, 1989.

FARO, Antônio José. Pequena história da dança. Rio de Janeiro: Jorge Zahar, 1986.

GASSNER, John. Mestres do teatro. vol. I. trad. de Alberto Guzik e J. Guinsburg. São Paulo: Pespectiva/EDUSP, 1974.

GILLAM, Robyn. Performance and drama in ancient Egypt. London: Gerald Duckworth $\&$ Co, 2006.

GINZBURG, Carlo. O queijo e os vermes: o cotidiano e as ideias de um moleiro perseguido pela inquisição. trad. de Maria Betânia Amoroso. São Paulo: Companhia das Letras, 1987.

MOUSSINAC, Léon. História do Teatro: das origens aos nossos dias. trad. de Mário Jacques. Amadora/Portugal: Bertrand, 1957.

PATERSON, Morton. The stagecraft of the revels office during the reign of Elizabeth. In: PROUTY, Charles (ed.). Studies of Elizabethan Theatre. North Haven (US): The Shoe String Press, 1961.

PIGNARRE, Robert. História do Teatro. trad. de Maia Pinto e Maria Gabriela de Bragança. $3^{\mathrm{a}}$ ed. Mem Martins/Portugal: Europa-América, 1979. 
PRUNER, Michel. La fabrique du théâtre. Paris: Armand Colin, 2005.

SCHECHNER, Richard. Environmental theater. New York: Hawthorn Books, 1973.

SEVERO, Lessandra Scherer e SILVA, Edinice Mei. Sistema Stanislavski: o processo criativo nas organizações. Revista de ciências da administração. Florianópolis, Universidade Federal de Santa Catarina, v. 8, n. 15, jan/jun 2006.

SILVA, Edinice Mei. A organização excelente: diretrizes para o grupo teatral. Tese (Doutorado em Engenharia de Produção) - Programa de Pós-Graduação em Engenharia de Produção, Universidade Federal de Santa Catarina, Florianópolis, 2001.

SOARES DOS SANTOS, Marlene. O teatro elizabetano. In: NUÑEZ, Carlinda Fragale Pate et alii. O teatro através da história. Vol. I: O teatro ocidental. Rio de Janeiro: Centro Cultural Banco do Brasil/Entourage Produções Artísticas, 1994. p. 69-97.

VALE, Flávia Janiaski. Produção e gestão no teatro de grupo como forma de construção de autonomia. 2008. 151 f. Dissertação (Mestrado em Teatro) - Programa de Pós-Graduação em Teatro, Universidade Estadual de Santa Catarina, Florianópolis, 2008. 